\title{
Concepções e referenciais da educação popular: a sistematização de experiências de seus protagonistas na Paraíba
}

\author{
Klebson Felismino Bernardo ${ }^{1} \mathbb{D}$ \\ Pedro José Santos Carneiro Cruz ${ }^{2}$
}

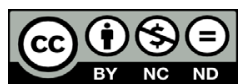

1. Universidade Federal da Paraíba, Brasil

klebsonbernardo987@hotmail.com

2. Universidade Federal da Paraíba, Brasil

Recibido: 04/03/2021

Revisado: 03/04/2021

Aprobado: 18/10/2021

Publicado: 01/01/2022

\section{Resumo}

O artigo apresenta aspectos concernentes à educação popular (EP). Trata-se de um estudo que tem como pano de fundo a percepção de protagonistas de experiências na Paraíba. O objetivo central é a reconstituição da história da EP nesse estado a partir do reconhecimento, valorização e registro da memória de alguns de seus principais atores, num processo investigativo que buscou promover a explicitação e sistematização das ideias, reflexões e trajetórias deles. O caminho investigativo adotado foi o da sistematização de experiências, em que entrevistas individuais semiestruturadas foram a estratégia para operacionalizar os dados. O quadro síntese releva um traço em comum: todos os entrevistados informaram ter o educador popular Paulo Freire como referência de inspiração em suas práticas. As definições acerca da EP tocaram prioritariamente os princípios basilares: o diálogo, o educador, o(s) saber(es) e a realidade. Assim, coletamos um portfólio com informações, reflexões e ideias, bem como um registro e documentação dos percursos, trajetórias e experiências das pessoas entrevistadas no campo da EP.

Palavras-chave: saberes, científico, diálogo, campo, popular

Para citar este artículo: Bernardo, K., \& Carneiro , P. (2022). Concepções e referenciais da educação popular: a sistematização de experiências de seus protagonistas na Paraíba. Praxis \& Saber, 13(32), e12261. https://doi.org/10.19053/22160159.v13.n32.2022.12261 


\title{
Concepciones y referencias de la educación popular: la sistematización de experiencias de sus protagonistas en Paraíba
}

\section{Resumen}

El artículo presenta aspectos relativos a la educación popular (EP). Este estudio tiene como telón de fondo la percepción de los protagonistas de experiencias en Paraíba. El objetivo central es la reconstrucción de la historia de la EP en dicho estado a partir del reconocimiento, la valoración y el registro de la memoria de algunos de sus principales actores, en un proceso de investigación que buscó promover la explicitación y la sistematización de sus ideas, reflexiones

y trayectorias. El método investigativo adoptado fue la sistematización de experiencias, en la que entrevistas individuales semiestructuradas fueron la estrategia fundamental para operacionalizar los datos. La tabla resumen muestra un hilo conductor: todos los entrevistados informaron tener al educador popular Paulo Freire como referente de inspiración en sus prácticas. Las definiciones sobre EP abordaron en especial los principios básicos: el diálogo, el educador, el(los) saber(es) y la realidad. De tal forma, recopilamos un portafolio con información, reflexiones e ideas, así como un registro y documentación de los caminos, trayectorias y experiencias de las personas entrevistadas en el campo de la EP.

Palabras clave: saberes, científico, diálogo, campo, popular

\section{Conceptions and references of popular education: the systematization of experiences of its protagonists in Paraíba}

\begin{abstract}
The article presents aspects concerning popular education (PE). This research has the perception of protagonists of experiences in Paraíba as a backdrop. The main objective is the reconstruction of the history of PE in the aforementioned state, based on the recognition, the appreciation, and the recording of the memory of some of its main participants, in an investigative process that sought to promote the explicitness and systematization of their ideas, reflections, and trajectories. The research method adopted was the systematization of experiences, in which individual semi-structured interviews were the strategy for operationalizing data. The summary table shows a common element: all the interviewees reported having the popular educator Paulo Freire as reference for inspiration in their practices. The definitions on PE addressed primarily the basic principles: dialogue, educator, knowledge, and reality. Thus, we collected a portfolio with information, reflections, ideas as well as a record and documentation of the paths, trajectories, and experiences of the interviewees in the field of PE.
\end{abstract}

Keywords: knowledge, scientific, dialogue, field, popular 
O presente artigo tem como objetivo apresentar as concepções e os referenciais orientadores da educação popular (EP), de acordo com a percepção de alguns de seus principais protagonistas. Resultou de uma pesquisa mais ampla, dedicada à reconstituição da história da EP no estado da Paraíba, a partir do reconhecimento, valorização e registro da memória de alguns de seus principais atores, num processo investigativo que promoveu a explicitação e, consequentemente, a sistematização das ideias, reflexões e trajetórias deles.

Inicialmente, compreendemos a EP como uma perspectiva do pensar e do fazer educacional; uma orientação teórico-metodológica para as realizações educacionais tanto nos espaços formativos institucionalizados como nos movimentos e práticas sociais, nas relações humanas, nas atividades e nas ações sociais em geral, bem como nos processos empreendidos no âmbito das políticas sociais públicas. Estudada e desenvolvida teoricamente por Paulo Freire e outros autores, a perspectiva da EP implica, na acepção de Calado (2014), um processo formativo protagonizado pela classe trabalhadora e seus aliados, continuamente alimentado pela utopia, em permanente construção de uma sociedade economicamente justa, socialmente solidária, politicamente igualitária e culturalmente diversa, dentro de um processo coerentemente marcado por práticas, procedimentos, dinâmicas e posturas correspondentes ao mesmo horizonte.

O movimento de EP vem, historicamente, se construindo e afirmando sua importância para a construção da cidadania voltada para a emancipação das pessoas. Diversos coletivos sociais e populares - como a Rede de Educação Cidadã (RECID), o Movimento dos Trabalhadores Rurais Sem Terra (MST), a Rede de Educação Popular e Saúde, a Articulação Nacional de Movimentos e Práticas de Educação Popular e Saúde, a Articulação Nacional de Extensão Popular (ANEPOP), dentre outros - têm mostrado reflexões e conhecimentos num processo de diálogo entre serviços, movimentos populares e espaços acadêmicos, para concretizar um projeto de sociedade mais justo e equânime, reiterando seu compromisso com a melhoria da qualidade de vida de todos os brasileiros e com a consolidação dos direitos sociais e humanos (Cruz, 2010; Neto, 1999).

A EP é um eixo teórico-metodológico orientador de ações no campo educacional e social. Desde os anos de 1950, processualmente, essa perspectiva foi se consolidando como um eixo estruturante sobre o qual se alicerçam trabalhos sociais, comunitários e pedagógicos, em que se acredita serem as atividades educativas estratégias elementares para a dinamização da promoção da cidadania, onde se estimula a proatividade da população, a interação cultural e o fortalecimento dos movimentos sociais, vitais para a emancipação e a conquista de condições de trabalho e de vida com qualidade, dignidade e alteridade (Calado, 2014; Cruz, 2010).

A EP surge em meio às perspectivas críticas de pensar a educação na América Latina, eé no final da década de 1950 que começa a se estruturar como teoria e prática social, através de uma ação pioneira do Serviço de Extensão da Universidade de Pernambuco, com ações de alfabetização com jovens e adultos. A partir dessa experiência, intelectuais e educadores voltam-se para questões populares, buscando trabalhar o homem, de forma pedagógica, com vistas a promover a criticidade a respeito da realidade e a possibilitar estratégias de luta e enfrentamento. Com isso, a EP passa a ser melhor elaborada teórica e metodologicamente como abordagem educativa, sendo também conhecida como método Paulo Freire, visto que ele foi um dos principais responsáveis pelo aperfeiçoamento filosófico desta abordagem da educação (Cruz, 2010; Cruz, 2015; Vasconcelos, 2013). 
Nessa caminhada, a EP tem se configurado como uma das estratégias utilizadas em diversos movimentos sociais, práticas populares e serviços sociais para impulsionar o controle social, através de práticas educativas no cotidiano dos serviços. A EP aponta um olhar, uma escuta, um fazer com, que se contrapõe à cultura autoritária dos serviços e exercita uma ética de convívio transformadora que propicia uma valorização do saber popular e do cidadão, fazendo ver aos profissionais o caráter educativo das ações de saúde. Assim, facilita a participação de importantes atores sociais da comunidade no processo de construção da cidadania (Albuquerque \& Stotz, 2004).

No estado da Paraíba, historicamente, foram construídas várias ações orientadas pela EP, com diferentes níveis de recurso material e humano, bem como com variadas conformações metodológicas e interfaces pedagógicas, atuando em distintas comunidades, instituições e cenários sociais. Algumas dessas experiências continuam em pleno andamento; outras foram extintas, enquanto muitas foram reconfiguradas e permanecem em construção com diferentes nuances e arranjos daqueles com os quais iniciaram suas atividades.

As vivências e experiências desenvolvidas no seio dessas várias atividades corroboraram para a deflagração de um rico processo de sistematização e de reflexão crítica, teórica e metodológica, resultando num significativo mosaico de produções acadêmicas e literárias acerca dessas experiências e, para além delas, sobre a educação brasileira, a educação de jovens e adultos, os processos de ensino e aprendizagem, a interface educativa de políticas públicas, $o$ ensino universitário e os movimentos sociais, dentre outros.

\section{Metodologia}

O presente estudo teve seu caminho investigativo pautado na pesquisa qualitativa, conforme fundamentado por Gadamer (1999) e Minayo (2008). Para seu desenvolvimento, utilizou-se da metodologia da sistematização de experiência para chegar aos objetivos almejados. Esta metodologia, empregada conforme os fundamentos estabelecidos por Holliday (2006a), serviu para verificar as condições do contexto em que se desenvolveram as práticas educativas das experiências pesquisadas, bem como os resultados esperados e inesperados obtidos no decorrer do processo. A estratégia de operacionalização da pesquisa constituiu de entrevistas semiestruturadas individuais (Minayo, 2008; Triviños, 1987).

O corpo de entrevistados foi composto por dez pessoas que tiveram um protagonismo na história das experiências de EP na Paraíba. Seu critério de inclusão envolveu aquelas pessoas que sistematizaram e publicaram experiências, reflexões e ideias no campo da EP, com produções escritas ou literárias. A escolha dos entrevistados deu-se a partir de consulta a grupos de pesquisa e coletivos que historicamente priorizam o estudo no campo da EP e sua interface com práticas sociais e populares, mais especificamente o Grupo de Pesquisa em Educação Popular e Saúde e o Grupo de Pesquisa em Extensão Popular, além da Rede de Educação Popular em Saúde, a ANEPOP, a RECID e o MST.

Nesta perspectiva, dentre dez indicados, foram contemplados necessariamente atores com experiências em diferentes tempos históricos, abrangendo necessariamente homens e mulheres. Como dito anteriormente, este artigo resulta de subprojeto de uma pesquisa mais ampla, cujo roteiro foi constituído das seguintes questões: 
1. Você se considera um/a educador popular? Por quê?

2. Como você se tornou um/a educador/a popular?

3. Ao longo de seu percurso, quais foram às temáticas ou as questões que mais despertaram o seu interesse?

4. Quais foram às ideias, as referências mais significativas/expressivas? Por quê?

5. Seria possível sintetizar um conceito de EP?

6. Em sua opinião, quais são os principais desafios e possibilidades da EP hoje?

7. Numa autoavaliação crítica, quais seriam suas principais contribuições - teóricas e práticas - à EP?

8. Como podemos fazer um levantamento de suas principais produções?

Nesta perspectiva, o estudo centra-se em analisar, por meio da ótica dos entrevistados, os referenciais e concepções da EP expressos por eles, particularmente quanto às respostas das questões 1, 2, 4 e 5, sem exclusão de respostas a outras questões que contemplem o foco deste manuscrito. Apesar de serem orientadas por um roteiro contemplando algumas questões significativas para o estudo, tais entrevistas foram pautadas pelo referencial da história oral (Selau, 2004), estando, portanto, plenamente abertas e livres às iniciativas dos entrevistados e aos vários aspectos, nuances e considerações que avaliassem ser oportuno compartilhar diante do objeto de estudo. Os depoimentos orais foram registrados por meio de filmagem em câmera digital e de gravador de voz em aparelho celular.

Esta pesquisa está em consonância com os preceitos que regem a portaria n. 466/2012 (Ministério da Saúde do Brasil, 2012) e foi submetida no Comitê de Ética e Pesquisa do Centro de Ciências Médicas da Universidade Federal da Paraíba. Antes de proceder com a coleta das informações cedidas pelos sujeitos do estudo, como pesquisadores explicamos clara, detalhada e precisamente os objetivos do estudo, expomos os instrumentos e o roteiro da entrevista, e entregamos cópia do Termo de Consentimento Livre e Esclarecido, que foi lido e, mediante concordância dos sujeitos, assinado.

Os dados descritos no estudo contaram com a aprovação dos entrevistados, como também houve autorização para revelação de suas identidades. A partir dessa relação no quadro, passouse à nova leitura do material transcrito com vistas à elaboração de sínteses finais, considerando a análise crítica e a problematização de todos esses aspectos na perspectiva da concepção metodológica dialética. De acordo com o entendimento de Holliday (1996), esta concepção metodológica vai muito além do que um procedimento de análise científico, visto que considera a realidade numa perspectiva de conhecê-la de forma crítica e ser capaz de transformá-la.

\section{Resultados e discussão}

\section{Concepções e referenciais da EP para os protagonistas da Paraíba}

Ao considerar a relevância e as contribuições para o contexto da EP, serão expostas (quadro 1) apenas as informações relativas à atuação dos sujeitos entrevistados com foco no conceito e 
nos referenciais da EP. Contudo, é importante ressaltar que a história desses autores e demais informações advindas da entrevista semiestruturada é de fundamental importância, porquanto constará dentro de outros materiais em fase de elaboração, a exemplo de livros e outros produtos.

Quadro 1 - Síntese das ideias dos protagonistas da EP na Paraíba

\begin{tabular}{|c|c|c|}
\hline Entrevistado & & Aspectos principais \\
\hline $\begin{array}{l}\text { Eymard Mourão } \\
\text { Vasconcelos }\end{array}$ & $\begin{array}{l}\text { Concepções } \\
\text { de EP }\end{array}$ & $\begin{array}{l}\text { A EP é uma teoria e uma prática pedagógica que surgiu na América Latina } \\
\text { em meados do século XX, com grande participação de Paulo Freire como } \\
\text { um pioneiro de sua sistematização, mas que está também muito marcada } \\
\text { por uma atitude pessoal do educador. Eu, particularmente, gosto de dizer } \\
\text { que se reconhece o educador popular pelo cheiro. Entre os elementos que } \\
\text { precisam estar presentes na essência desse cheiro, está a atitude de gostar } \\
\text { do diálogo; de ter curiosidade para estar sempre buscando compreender } \\
\text { mais profundamente a realidade; de investir na escuta das pessoas - } \\
\text { principalmente, as que costumam estar silenciadas e marginalizadas - e } \\
\text { dos movimentos sociais para avançar nessa compreensão; de ter um } \\
\text { compromisso e uma solidariedade com os que sofrem; de valorizar e de se } \\
\text { integrar em iniciativas e lutas feitas por coletivos; e de ter um jeito amoroso } \\
\text { de se relacionar com as pessoas. }\end{array}$ \\
\hline
\end{tabular}

As referências de Eymard Vasconcelos, no campo da EP, estão fortemente

Referenciais ligadas com a teologia da libertação e com o pensamento de intelectuais como Paulo Freire, Miguel Arroyo e Victor Vincent Valla.

Tomo EP como um processo contínuo de humanização, um processo formativo, protagonizado pelas classes populares, em todos os seus momentos, desde

\begin{tabular}{|c|c|c|}
\hline o & Concepções & $\begin{array}{l}\text { protagonizado pelas classes populares, em todos os seus momentos, desde } \\
\text { sua concepção, planejamento, execução, avaliação... [um processo que] exige } \\
\text { superar limites... assegurando condições para que se descubram os limites e as }\end{array}$ \\
\hline
\end{tabular}
ssoa.

Referenciais e Rosa Luxemburgo, mas também por os contemporâneos como Paulo Freire e José Comblin.

A teoria descolada da prática é a contradição... O cerne da ideia de EP é justamente a ação inserida e comprometida, partindo do fato de que o educador é um educando e o educando é um educador... Não basta ler um livro de Paulo Freire para virar educador popular, não é bem assim. Tudo tem a ver com as experiências da vida da gente, porque, se há uma forma de trabalho em que a Concepções personalidade do educador é fundamental, então, essa é a EP, porque é um corpo de EP a corpo, sem aula preparada para despejar em cima do outro, queira ele ouvir ou não queira. Tem que ser capaz de improvisar, ou seja, de responder a demanda do outro na hora. Tem que ter uma experiência de vida, ter uma visão de mundo bastante aberta. Então, essa ideia é fundamental: o educador-educando e o educando-educador. Há dois diferentes saberes, que são complementares, que são críticos um frente ao outro, o diálogo como meio fundamental e a ação como

Maria Valéria Rezende resultado, porque a ação vai produzir novo saber.

Ela é fortemente influenciada pelo pensamento cristão e sua relação com a construção do processo educacional humanizador e libertador. Entre algumas referências com as quais dialoga, podem ser citadas pessoas como Paulo Freire, Raúl Leis, Marco Raúl Mejía, assim como outros educadores populares ligados a Red Alforja, como Oscar Jara e Carlos Nuñez Hurtado. Muitos desses autores foram companheiros de Valéria Rezende na juventude e na construção de Referenciais experiências em EP. Valéria acentua que, com eles, foi formando e organizando o pensamento e a metodologia da EP ao longo de várias décadas. Muitos deles se dedicaram a sistematização e a elaboração teórica mais sistematicamente por passarem a atuar mais intensamente na universidade, priorizando assim a sistematização e desenvolvimento coletivo de suas metodologias. Nesse período, Valéria continuou no trabalho de base e, apenas alguns anos depois, se tornou escritora, especialmente de obras de ficcão inspiradas por sua experiência como educadora popular. 


\begin{tabular}{|c|c|c|}
\hline \multirow[t]{2}{*}{$\begin{array}{l}\text { José Francisco } \\
\text { de Melo Neto }\end{array}$} & $\begin{array}{l}\text { Concepções } \\
\text { de EP }\end{array}$ & $\begin{array}{l}\text { De acordo com a minha vivência, pode-se dizer que EP é um fenômeno humano. } \\
\text { Ela não ocorre em outras espécies. É somente nosso. Ela não é só de ensino, } \\
\text { mas também de aprendizagem. Um manual qualquer de educação apresenta uma } \\
\text { visão autoritária e dominante embutida na concepção de que o professor é o } \\
\text { que ensina. Por isso, a dialética arrasta para a outra dimensão educativa que é a } \\
\text { aprendizagem. Dessa forma, há uma salutar contaminação da compreensão de } \\
\text { educação de Freire. }\end{array}$ \\
\hline & Referenciais & $\begin{array}{l}\text { Suas bases teóricas metodológicas estão alicerçadas no marxismo, que, para ele, } \\
\text { se aproximam de toda a sua formação cristã e freiriana. }\end{array}$ \\
\hline \multirow[t]{2}{*}{$\begin{array}{l}\text { Severino Bezerra } \\
\text { da Silva }\end{array}$} & $\begin{array}{l}\text { Concepções } \\
\text { de EP }\end{array}$ & $\begin{array}{l}\text { Não existe EP distante de seus sujeitos, da prática e da realidade... A perspectiva } \\
\text { da EP deve ser estabelecer não qualquer diálogo, mas um com compromisso, um } \\
\text { diálogo de transformação. }\end{array}$ \\
\hline & Referenciais & $\begin{array}{l}\text { Entre as suas referências, a marca da teologia da libertação se faz bastante } \\
\text { presente, assim como o pensamento e influência de Paulo Freire. }\end{array}$ \\
\hline \multirow[t]{2}{*}{$\begin{array}{l}\text { Kátia Suely } \\
\text { Queiroz } \\
\text { Silva } \\
\text { Ribeiro }\end{array}$} & $\begin{array}{l}\text { Concepções } \\
\text { de EP }\end{array}$ & $\begin{array}{l}\text { A EP não se apresenta apenas como perspectiva educativa, mas como uma } \\
\text { forma de ver o mundo, de se relacionar com as pessoas, de estar e de ser na } \\
\text { sociedade. Então, na minha vida, procuro pautar meu comportamento e relações } \\
\text { interpessoais com o que eu aprendi na EP, tanto no respeito às diferenças, quanto } \\
\text { na construção do diálogo, que é muito difícil, sobretudo, por opção política e } \\
\text { pelas classes populares. Enquanto docente, seja na pesquisa, na extensão ou no } \\
\text { ensino, procuro me guiar, o mais coerentemente possível, por esses princípios e } \\
\text { por formas dialogais de me relacionar com o outro. }\end{array}$ \\
\hline & Referenciais & $\begin{array}{l}\text { Entre as referências citadas por ela, podem ser destacadas pessoas como: Paulo } \\
\text { Freire, Dermeval Saviani, Moacir Gadotti, Carlos Rodrigues Brandão, Victor } \\
\text { Vincent Valla e Eymard Mourão Vasconcelos. }\end{array}$ \\
\hline \multirow[b]{2}{*}{ Fernando Abath } & $\begin{array}{l}\text { Concepções } \\
\text { de EP }\end{array}$ & $\begin{array}{l}\text { EP, para mim, é um processo humano, companheiro, coletivo, de aprendizagem } \\
\text { mútua, de solidariedade, de entendimento que não sou o único, que não sou mais } \\
\text { importante; esse processo humano que nos faz reconhecer a nossa necessidade } \\
\text { do outro, que não me basto sozinho, que não sou mais importante que ninguém. } \\
\text { Foi isso que aprendi com a EP. }\end{array}$ \\
\hline & Referenciais & $\begin{array}{l}\text { Apontou, enquanto referências iniciais, Paulo Freire e a Pedagogia do Oprimido, } \\
\text { no sentido da EP como prática de liberdade, além de Augusto Pinto Boal, com } \\
\text { sua relevante contribuição a partir do Teatro do Oprimido, em que alia o teatro } \\
\text { com a ação social, grande referência para o teatro brasileiro. Ainda, relaciona } \\
\text { questões filosóficas e práticas relativas à identidade cultural, a partir de Manuel } \\
\text { Castells, que permearam interligadas ao Teatro Pedagógico, pelo autor Flávio } \\
\text { Desgranges, que se preocupa com a reflexão sobre a cena e recupera Boal. No } \\
\text { que se refere à metodologia da pesquisa-ação, referencia Michel Thiollent e } \\
\text { Carlos Brandão, entre outros. }\end{array}$ \\
\hline \multirow[t]{2}{*}{ Socorro Borges } & $\begin{array}{l}\text { Concepções } \\
\text { de EP }\end{array}$ & $\begin{array}{l}\text { A EP é uma concepção de mundo, é uma visão de mundo, é um projeto de } \\
\text { sociedade. Ela não é só um método epistemológico e de conhecimento com } \\
\text { várias metodologias que posso utilizar, mas compreender a sociedade e a } \\
\text { realidade vivida. A EP são as experiências contextualizadas daquele grupo, } \\
\text { daquele momento, daquela realidade, daquele chão, daquelas relações } \\
\text { sociais. É a desconstrução de um sistema, é essa utopia que precisa ser vivida } \\
\text { nas organizações sociais e que se encontra com outros projetos de uma } \\
\text { sociedade melhor, tendo princípios que nos ajudam e norteiam nossa ação: o } \\
\text { respeito à sabedoria e à história de cada uma e de cada um, a amorosidade, } \\
\text { o compartilhamento e a construção de novos saberes a partir da troca de } \\
\text { conhecimentos, a desconstrução de saberes hegemônicos que servem ao } \\
\text { capitalismo, a ação diária em prol da transformação coletiva do mundo. }\end{array}$ \\
\hline & Referenciais & $\begin{array}{l}\text { Tem referência na teologia da libertação, e a partir das ideias de Paulo Freire, } \\
\text { Leonardo Boff, Clodovis Boff, Oscar Jara, Irmã Augustinha, Frei Betto, } \\
\text { Francisco Gutierrez, Carlos Mesters e José Comblin. }\end{array}$ \\
\hline
\end{tabular}




\begin{tabular}{|c|c|c|}
\hline \multirow[t]{2}{*}{$\begin{array}{l}\text { Luiz Gonzaga } \\
\text { Gonçalves }\end{array}$} & $\begin{array}{l}\text { Concepções } \\
\text { de EP }\end{array}$ & $\begin{array}{l}\text { A EP nos ajuda a romper com os preconceitos e os recortes muito fechados do } \\
\text { conhecimento técnico e científico, que perde muitas vezes a noção do limite, } \\
\text { do humano, da natureza. A EP sempre estará ligada ao que mantém a vida. Ela } \\
\text { ajuda a pensar com os sujeitos que estão em contato mais denso da natureza a } \\
\text { observar os limites dos próprios artefatos e recursos que os criam. }\end{array}$ \\
\hline & Referenciais & $\begin{array}{l}\text { Destaca a importância de Paulo Freire, os estudos de Maturana, e aponta em } \\
\text { vários momentos autores como Sócrates e Platão. }\end{array}$ \\
\hline \multirow[t]{2}{*}{$\begin{array}{l}\text { Maria José } \\
\text { Nascimento } \\
\text { Moura Araújo }\end{array}$} & $\begin{array}{l}\text { Concepções } \\
\text { de EP }\end{array}$ & $\begin{array}{l}\text { Quando você ensina e, ao mesmo tempo, aprende, tendo consciência de que } \\
\text { ninguém sabe tudo e de que ninguém não sabe nada, ninguém é ignorante de } \\
\text { saber nenhum. Sempre temos o que aprender se estou aberta a isso. Quem ensina } \\
\text { aprende ao ensinar e quem aprender ensina ao aprender. Como Paulo Freire } \\
\text { diz: "É só na prática, na vivência com o outro que trocamos saberes", a cada } \\
\text { dia, a cada grupo de alunos que recebemos, um novo mundo de inquietações e } \\
\text { conhecimentos. EP, de qualquer natureza, ambiental, de saúde, de escolaridade, é } \\
\text { você estar sempre nesse ponto de humildade e de clareza do seu saber escutando } \\
\text { e aprendendo com o outro como produto de uma troca. Assim, ninguém é } \\
\text { melhor ou sabe mais que o outro. Temos, apenas, saberes diferentes, cabe saber } \\
\text { respeitá-los em comunhão e produção de novos saberes. A ação-reflexão-ação, a } \\
\text { práxis freiriana, não pode partir apenas do saber do outro. }\end{array}$ \\
\hline & Referenciais & $\begin{array}{l}\text { Paulo Freire foi uma das referências apontadas. Além disso, ela fez menção } \\
\text { a outras leituras que referenciam a filosofia freiriana como Magda Soares. } \\
\text { Ela referencia no letramento e na alfabetização Emília Ferreira, que aborda } \\
\text { muitos elementos da cognição e do universo de leitura-escrita do adulto. Faz-se } \\
\text { necessário destacar também as teorias de Luckesi na avaliação de aprendizagem; } \\
\text { Philippe Perrenoud, com aprofundamento de respostas da teoria freiriana; e } \\
\text { Fernando Becker, que trabalha na linha de formação de educadores populares. }\end{array}$ \\
\hline
\end{tabular}

\section{Análise das concepções de EP na ótica dos entrevistados}

Levando em consideração as concepções evidenciadas pelos entrevistados no Quadro 1, Síntese das ideias dos protagonistas da EP na Paraíba, podemos compreender e ampliar um pouco mais a discussão sobre como e de que forma os educadores populares compreendem concepções alicerçantes do fazer e agir dos sujeitos. Foi possível identificar nas falas dos entrevistados a relação da EP com a construção do sujeito pensante, crítico-reflexivo. Compreende-se ainda, como bem esclarece alguns educadores, a importância do saber vivido, das experiências e saberes guiado através da concepção de EP. Quanto a esse princípio sobre a experiência cotidiana, na obra póstuma Pedagogia dos sonhos possíveis, Freire (2001) nos traz que, seja ele como pessoa, seja como educador, ao pensar na sua prática educativa e no fazer a prática educativa, declara ter respeito ao educando:

E um grande respeito, também, pelo saber "só de experiências feito", como diz Camões, que é exatamente o saber do senso comum. Discordo dos pensadores que menosprezam o senso comum, como se o mundo tivesse partido da rigorosidade do conhecimento científico. De jeito nenhum! A rigorosidade chegou depois. (p. 232)

A partir desse pensamento, o autor nos incita a considerar que o agir e o pensar na cotidianidade promove nos sujeitos a possibilidade de fortalecer suas ideias, suas lutas, uma vez que são saberes construídos nas relações com o outro, por meio do diálogo, de forma que não existem saberes mais e saberes menos, sendo a dimensão do saber um dos eixos centrais da EP. Nessa perspectiva, vale ressaltar que os conhecimentos são produzidos nas relações afetuosas e até mesmo de conflitos, pois é nas relações também conflituosas que novos saberes 
são produzidos. Essa relação é marcada pela valorização do saber do outro e pela escuta.

Para Albuquerque (2020), "a leitura crítica do mundo mediada coletivamente revela o caráter político na sua concepção educacional. [...] o ato educativo se faz na amorosidade, acolhendo para além do verbal outros sentidos e expressividades” (p. 3). Essa dimensão de experiências construídas na cotidianidade também coaduna com o que a entrevistada Maria Valéria Rezende aborda ao destacar que se faz necessário esse intercâmbio de saberes, que os sujeitos tenham uma visão de mundo bastante aberta, pois esse é o princípio basilar para entender o outro e as suas subjetividades e particularidades; é ter essa consciência crítica e aberta quanto ao outro.

Torres (2018) contribui com a discussão ao oportunizar um debate bastante contextualizado com o que Maria Valéria Rezende traz com relação à visão de mundo e, atrelado a isso, o agir crítico. Para ele:

En un sentido aún más amplio, podemos reconocer como críticas, las actitudes, posiciones $\mathrm{y}$ acciones de colectivos sociales que resisten a situaciones o condiciones que interpretan como injustas, y frente a las cuales despliegan un conjunto de sentires, saberes y sabidurías portadores de sentidos crítico [Num sentido ainda mais amplo, podemos reconhecer como críticas, as atitudes, posicionamentos e ações dos coletivos sociais que resistem a situações ou condições que interpretam como injustos, e diante dos quais exibem um conjunto de sentimentos, saberes e sabedorias que carregam significados críticos]. (p. 176, tradução nossa).

O autor ainda acrescenta o pensamento crítico sobre a realidade e sobre as situações de injustiça que estão presentes nas relações sociais. Além disso, ele sinaliza que os setores populares, nos diversos espaços de interação, são forjados por experiências e saberes que produzem uma multiplicidade de conhecimentos e que, através dessa polissemia, corroboram para a produção do novo, endossado nas experiências construídas no fazer cotidiano dos sujeitos, ou seja, da realidade e da pluralidade de cada sujeito (Torres, 2007). De acordo com o entendimento de Mejía (2016),

La tradición freireana de la educación popular se constituye desde el diálogo de saberes, en el cual el educando enuncia su mundo y sale del silencio [A tradição freiriana de educação popular se constitui a partir do diálogo de saberes, no qual o aprendiz anunciase no mundo e sai do silêncio]. (p. 47, tradução nossa)

Pode-se compreender que a EP tem como uma de suas incumbências a transitivação da passividade, da imposição para o inédito viável. No que tange ao conceito de EP, os entrevistados, em vários momentos, trouxeram para o debate a $\mathrm{EP}$ como sendo um processo formativo, que vai constituindo o sujeito por meio de suas experiências, saberes e subjetividades.

Segundo Schönardie (2018), "uma das questões de maior centralidade na educação popular é a sua perspectiva emancipatória. Sujeitos e coletivos se constroem protagonistas de sua história” (p. 30). Através dessas dimensões, podemos considerar que a EP não esgota enquanto processo formativo, mas desabrocha, necessariamente, como uma frente de emancipação, que olha para o indivíduo em sua totalidade, enquanto protagonista de sua história, com seus diferentes saberes e experiências, que constitui o seu agir e pensar na sociedade. Por este 
motivo, a EP desponta como um solo fértil de diálogo com a realidade, entre os diferentes saberes, de ruptura com a ideologia de ser mais e saber menos, assim como de valorização dos protagonistas, de suas experiências e saberes.

Quadro 2 - Síntese das dimensões identificadas por meio das falas dos entrevistados

\begin{tabular}{cc}
\hline Dimensão & Número de citações dessa dimensão \\
Diálogo & 5 \\
Educador & 8 \\
Saber(es) & 8 \\
Realidade & 4 \\
\hline
\end{tabular}

Pela ótica dos entrevistados, no Quadro 2, Síntese das dimensões identificadas por meio das falas dos entrevistados, o diálogo é uma das questões fundantes quanto à concepção de EP. Na linha de pensamento de Fleuri (2019), o diálogo é uma das dimensões mais importantes na perspectiva da EP. Explicita-se como dimensão permeada em experiências culturais distintas, dentro das quais se expressa como uma possibilidade de luta, resistência e fortalecimento do outro com o outro, ou seja, sendo matéria-prima desse processo o encontro de saberes, numa busca por novas alternativas de viver em sociabilidade, de forma democrática, libertária, emancipatória, amorosa e respeitosa com o outro.

$\mathrm{Na}$ acepção dos entrevistados, o diálogo não é um processo apenas raciocinante, mas se desvela num encontro dos atores e autores populares entre si, com o mundo e com todas as suas dimensões, ou seja, corpos, mentes, sentidos, emoções, saberes e experiências dotadas de conhecimentos, que são construídos através do agir e do pensar diariamente, das trocas e dos conflitos. Pelo diálogo, os setores populares promovem uma releitura do que é o fazer e o ser social. É na coletividade com esses atores e autores populares que somos convidados a observar a realidade também sob outra ótica (Freire, 2013).

Contudo, a efetivação desse diálogo ainda é um desafio, principalmente diante do cenário hegemônico do cotidiano da educação e outros espaços em que opera a ação humana - por causa do autoritarismo, antidemocracia e paternalismo - , que se configura como uma cultura avessa a práticas transformadoras, cultura que ataca esses protagonistas por meio da opressão, silenciamento e do cerceamento de liberdade. Como categoria fundante, o diálogo defendido pelos entrevistados é aquele envolvido com o outro, desintoxicado de determinismos e autoritarismo.

Paralelo a isso, Oliveira e Cananéa (2016) consideram que o diálogo "move a educação popular e a educação ao longo da vida numa perspectiva da educação popular, seja esta pautada nas suas origens históricas que fundamentam seus ideais primórdios ou na sua reformulação para atender às necessidades atuais da sociedade” (p. 1).

Conforme expresso nas entrevistas, a concepção de EP aponta para um olhar do educador também como sujeito aprendente, de modo que o seu conhecimento não finda na formação inicial. Ninguém é sábio o bastante que não precise do outro, das relações, sejam ela afetuosas ou não. Por este motivo, como aponta Freire (2013), é preciso ter fé no outro e assumir uma postura humilde, reconhecendo que o outro sempre tem algo a contribuir. Logo, a relação entre educadores e educandos, deve ser permeada na solidariedade, no respeito ao outro, 
no reconhecimento de que não há verdade absoluta, como também é preciso lutar contra a ideologia de conhecimentos hegemônicos.

Nessa relação com os campos ativos e polissêmicos, como as comunidades, Valla (1993) acredita existir dois pontos cruciais que ajudam a entender como as classes subalternas são enxergadas. O primeiro é que há uma enorme dificuldade em compreender que esses setores possuem conhecimento e, principalmente, que são capazes de produzi-lo. Somado a isso, está a concepção de que esses sujeitos são incapazes de interpretar aspectos importantes na sociedade e, muito menos, opor-se a qualquer injustiça. O segundo aspecto parte da nossa falta de compreensão e insensibilidade de entender o que o outro tem a falar, ou seja, para entendê-los é preciso estar disposto a ouvi-los e ter humildade para perceber a polissemia de saberes e conhecimentos presentes nesses espaços vivos. De acordo com o pensamento de Gonzalez et al. (2018),

por viver em uma sociedade que possui uma ideologia neoliberalista onde impera o conceito de meritocracia, o lugar de fala das minorias é, quase por via de regra - se não fossem as lutas e o empenho dos movimentos sociais - suprimido. (p. 2).

Como resultado disso, acaba por criar o afastamento dos setores populares e a academia, uma vez que os setores populares não se sentem representados pela universidade, visto que a comunidade acadêmica expressa cada vez seu poder e elitismo, e os saberes produzidos nos setores populares são por sua vez minimizados e ignorados.

A EP faz-se com o outro, no processo de construção compartilhada do conhecimento, assim como no cuidado com o outro, na sensibilidade para entender que cada indivíduo tem sua historicidade, seu repertório, ou seja, experiências que são constituintes da sua identidade. É importante salientar que a EP, como explicita Socorro Borges, no quadro 1 sobre Síntese das ideias dos protagonistas da EP na Paraíba, é "a desconstrução de saberes hegemónicos que servem ao capitalismo", ou seja, essa concepção freiriana não nega aqueles saberes tidos como do senso comum, pelo contrário, é através desses conhecimentos que a EP se delineia.

\section{Análise dos referenciais da EP na ótica dos entrevistados}

Quadro 3 - Referenciais da EP mais apontados conforme os entrevistados

\begin{tabular}{ll}
\hline \multicolumn{1}{c}{ Autores referência } & Número de citações desses autores \\
\hline Paulo Freire & 10 \\
Victor Vincent Valla & 2 \\
José Comblin & 2 \\
Oscar Jara Holliday & 2 \\
Carlos Rodrigues Brandão & 2 \\
\hline
\end{tabular}

O quadro 3, Referenciais da EP mais apontados conforme os entrevistados, apresenta os referenciais da EP mais comentados pelos entrevistados. Muitos deles destacaram Freire como sendo uma das principais referências quando se trata de EP, seguido da marca da teologia da libertação. Demais referências, como Leonardo Boff, Clodovis Boff, Oscar Jara, 
Irmã Augustinha, Frei Betto, Francisco Gutierrez, Carlos Mesters, José Comblin, Dermeval Saviani, Moacir Gadotti, Carlos Rodrigues Brandão, Victor Vincent Valla, Eymard Mourão Vasconcelos, Miguel Arroyo, Raúl Leis e Marco Raúl Mejía, assim como outros educadores populares ligados a Red Alforja, como Carlos Nuñez Hurtado e outros, foram elencados.

É possível observar que todos os educadores destacaram Freire como basilar quando nos referimos à educação e, especialmente, à EP. De acordo com os entrevistados, Freire é a maior representação para a perspectiva da educação. Além disso, apontaram que esta referência é inspiração para a construção do fazer e do ser social, como forma de entender os espaços em que estão inseridos, como também na compreensão do inacabamento do ser humano e, mais do que isso, na possibilidade de educar o olhar quanto aos vários espaços de interação, de desenvolvimento e de resistência, a exemplo dos setores populares.

Para Gadotti (2007), Freire trouxe muitas contribuições para a educação, sempre com um olhar transformador e de sensibilidade com o outro e com a natureza. Aponta que, através de suas obras, tem contribuído no pensar e no agir de muitos profissionais quanto à ação pedagógica e a suas práticas, numa possibilidade de incitar esses sujeitos a produzirem o conhecimento crítico-reflexivo com o outro e com os espaços dotados de significados e sentidos. Freire coloca-nos as virtudes como exigências ou virtudes necessárias à prática educativa transformadora. Como exemplo dessas virtudes, têm-se: a tolerância e a coerência, teoria e prática, simplicidade, o legado de luta e de esperança, práxis, transdisciplinaridade etc.

Outro referencial que também contribui para a concepção de EP e para a compreensão do sujeito social e crítico é Valla. Ele traz uma discussão bastante significativa quanto à importância de ouvir as falas das classes subalternas, visto que os setores populares não são ouvidos, como também são vistos como espaços não pensantes, e a que o conhecimento popular dos indivíduos é irrelevante. Para Valla (1996), "nós oferecemos nosso saber por que pensamos que o da população é insuficiente e, por esta razão, inferior, quando, na realidade, é apenas diferente" (p. 179).

Expressa-se ainda como base na ótica dos entrevistados a importância de José Comblin para a EP. Alicerçado no pensamento de Comblim e no que Valla defende quanto à participação popular, entendemos ser necessário fortalecermos as bases e incitar a participação de todos, rumo à produção de conhecimento com as classes populares e à possibilidade de reorientação das práticas universitárias quanto ao diálogo com as comunidades, mesmo aquelas orientadas pela EP. Conforme aponta Comblin (1988), "a manifestação da liberdade é o serviço mútuo voluntário no amor... sem constrangimento, sem pressão, sem alienação da própria vontade” (p. 53).

Para Holliday (2006b), no que concerne a essa atmosfera preocupante e desumana, "são necessárias uma busca e uma reflexão em torno dos fundamentos filosóficos, políticos e pedagógicos de um paradigma educacional que oriente as perspectivas de transformação social e a formação plena das pessoas" (p. 238), objetivando a constituição de novas estruturas e relações sociais fundamentadas no respeito ao outro e ao espaço de vivência, assim como na solidariedade, justiça e equidade. Esse repensar sobre nossas ações é necessário, do mesmo modo que lutar coletivamente para a construção de uma sociedade democrática, dialógica, libertária e emancipadora. 
Alguns entrevistados pontuaram sobre estarem fortemente influenciados pelo pensamento cristão, assim como do marxismo, e nas raízes intelectuais dos pensadores internacionalmente relevantes como Karl Marx e Rosa Luxemburgo. Com base nessas compreensões, podemos considerar a EP como um processo capaz de formar sujeitos autônomos, críticos-reflexivos, capazes de romper com a ordem social dominante, de problematizar, de contextualizar, de interpretar sua realidade de forma consciente como também de criar espaços de participação compromissada com o outro e com a diversidade de saberes, negando padrões determinados pela sociedade e verdades absolutas entre outros protagonismos.

\section{Conclusões}

Numa atmosfera de reflexões, concepções, informações e experiências, o estudo foi capaz de trazer, de forma crítica-reflexiva, elementos fundantes da EP, como o diálogo, os saberes construídos na cotidianidade e a realidade como cenário de (re)construção de nossas ações de forma consciente e politizada. Os educadores populares de referência no estado da Paraíba trouxeram elementos constituintes de seu fazer social e docente e se posicionaram enquanto sujeitos inconclusos e aprendentes. Elucidaram a importância de se construir espaços de diálogo numa perspectiva humanizada e respeitosa com o outro e com suas singularidades.

Por meio do ser e estar no mundo, os educadores entrevistados fertilizaram ainda mais a EP na Paraíba, pois foram capazes de experimentar na prática momentos de produção de conhecimentos diversos com o protagonismo desses atores populares. Com base nas experiências dos educadores populares explicitadas no estudo, notou-se a necessidade de uma discussão ainda mais compromissada com as classes populares, visto que se delineiam em projetos de extensão orientados pela EP alguns entraves que dificultam a efetivação de uma relação, de fato, horizontalizada.

Além disso, o autoritarismo e os roteiros prontos e acabados não compreendem o processo de construção coletiva-humana e respeitosa que estão imbricados na EP. Também foi evidenciada nas falas dos entrevistados a relevância de se desintoxicar de preconceitos e roteiros predefinidos que engessam e descaracterizam o que Freire nos alerta sobre a EP, como sendo uma categoria fundante para a construção coletiva com os espaços populares, comunidades e periferia com os contextos institucionalizados.

A partir das dimensões apontadas pelos entrevistados, somos incitados a pensar que a EP tem uma matriz pedagógica problematizadora, emancipatória, que resulta numa pedagogia da pergunta. Deste modo, é por meio desses princípios que a nossa ação tem cada vez mais relevância e nos provoca a refletir e agir conscientemente sobre nossas ações, visto que, em nossa realidade vivida, estamos imersos num mundo de complexidade, de trocas, de saberes e de conhecimentos. Logo, somos compreendidos enquanto sujeitos políticos, e é através dessas experiências que nos constituímos com os outros sujeitos críticos e conscientes, denunciando injustiças, práticas pedagógicas autoritárias e negligentes. Em razão disso, faz-se necessário exercitarmos a práxis, sendo este um movimento permanente.

\section{Referências}


Albuquerque de, C. (2020). Educação Popular e decolonialidade: resistências, reexistências e potências para um cuidado inclusivo na saúde e projetos coletivos para o "Bem viver". Interface - Comunicação, Saúde, Educação, (25), e200537. https://doi.org/10.1590/Interface.200537

Albuquerque de, P., \& Stotz, E. (2004). A educação popular na atenção básica à saúde no município: em busca da integralidade. Interface - Comunicação, Saúde, Educação, 8(15), 259-274. https://doi. org/10.1590/S1414-32832004000200006

Calado, A. (2014). Educação popular como processo humanizador: quais protagonistas? Em P. Cruz, A. Vasconcelos, P. Souza, A. Tófoli, D. Carneiro, \& C. Alencar (Orgs.), Educação popular e nutrição social: reflexões e vivências com base em uma experiência (pp. 355-375). UFPB.

Comblin, J. (1998). O Espírito Santo e a libertação. Vozes.

Cruz, P. (2010). Extensão popular: a pedagogia da participação estudantil em seu movimento nacional [Dissertação de Mestrado publicada]. Universidade Federal da Paraíba. Repositório Institucional da UFPB. https://repositorio.ufpb.br/jspui/handle/tede/4749.

Cruz, P. (2015). Agir crítico em nutrição: uma construção pela educação popular [Tese de Doutorado publicada]. Universidade Federal da Paraíba. Repositório Institucional da UFPB. https://repositorio. ufpb.br/jspui/handle/tede/8573.

Fleuri, R. (2019). Conversidade: diálogo entre universidade e movimentos sociais. Editora do CCTA.

Freire, P. (2001). Pedagogia dos sonhos possíveis. Editora da UNESP.

Freire, P. (2013). Pedagogia do oprimido. Paz e Terra.

Gadamer, H. (1999). Verdade e Método. Vozes.

Gadotti, M. (2007). Paulo Freire e a educação popular. Produção de terceiros sobre Paulo Freire.

Gonzalez, A., Pereira, R., \& Pereira, V. (2018). Os saberes populares e seu lugar na universidade: as relações de poder no âmbito acadêmico [Palestra]. 17a Mostra da Produção Universitária - MPU. Rio Grande/ RS, Brasil. https://mpu.furg.br/images/17aMPU/TrabalhosSI/s16.pdf

Holliday, O. (2006a). Para sistematizar experiências. Ministério do Meio Ambiente.

Holliday, O. (2006b). Ressignifiquemos as Propostas e Práticas de Educação Popular Perante os Desafios Históricos Contemporâneos. Em P. Pontual, \& T. Ireland (Orgs.). Educação popular na América Latina: diálogos e perspectivas (pp. 233-239). Edições MEC.

Mejía, M. (2016). Diálogo-confrontación de saberes y negociación cultural. Ejes de las pedagogías de la educación popular: una construcción desde el sur. Educar em Revista, (61), 37-53. https://doi. org/10.1590/0104-4060.47205

Minayo, M. (2008). O desafio do conhecimento: pesquisa qualitativa em saúde. Cadernos de Saúde Pública, 8(3), 342-344. http://dx.doi.org/10.1590/S0102-311X1992000300013

Ministério da Saúde do Brasil. (2012, 12 de dezembro). Resolução No 466. https://bvsms.saude.gov.br/ bvs/saudelegis/cns/2013/res0466_12_12_2012.html

Neto, J. (1999). Educação popular: uma ontologia. Em J. Neto, \& A. Scocuglia (Orgs.), Educação Popular: outros caminhos (pp. 31-75). UFPB.

Oliveira, A., \& Cananéa, F. (2016). Diálogo na educação popular e na educação ao longo da vida. https:// educacaopublica.cecierj.edu.br/artigos/16/23/dilogo-na-educao-popular-e-na-educao-ao-longo- 
da-vida

Schönardie, P. (2018). A educação popular em tessitura com as políticas públicas. Revista de Educação Popular, 17(1), 28-44. https://doi.org/10.14393/REP-v17n12018-art02.

Selau, M. (2004). História oral: uma metodologia para o trabalho com fontes orais. Esboços, 11(11), $217-$ 228. https://periodicos.ufsc.br/index.php/esbocos/article/view/486/9887

Torres, A. (2007). La educación popular. Trayectoria y actualidad. El Búho.

Torres, A. (2018). ¿Dónde está lo crítico de la Educación Popular? Em A. Guelman, F. Cabaluz, \& M. Salazar, (Eds.). Educación popular y pedagogías críticas en América Latina y el Caribe: corrientes emancipadoras para la educación pública del Siglo XXI (pp. 173-190). CLACSO.

Triviños, A. (1987). Introdução à pesquisa em ciências sociais: a pesquisa qualitativa em educação. Atlas.

Valla, V. (1993). Educação popular e conhecimento: A monitoração civil dos serviços de saúde e educação nas metrópoles brasileiras. Em V. Valla, \& E. Stotz (Orgs.), Participação popular, educação e saúde: teoria e prática (pp. 101-112). Relume Dumará

Vasconcelos, A. (2013). Práticas Educativas em Segurança Alimentar e Nutricional: a experiência da Estratégia Saúde da Família em João Pessoa PB [Tese de Doutorado publicada]. Escola Nacional de Saúde Pública Sergio Arouca. Repositório Institucional da Fiocruz. https://www.arca.fiocruz.br/ handle/icict/14208. 